\title{
Extension System for Improving the Management of Vegetable Cropping Systems
}

\author{
Theofrida J. Maginga ${ }^{1 *}$, Thibault Nordey ${ }^{2}$, Mussa Ally ${ }^{1}$ \\ ${ }^{1}$ Department of Information Technology and System Development, The Nelson Mandela African Institution of Science and \\ Technology, Arusha, TANZANIA \\ 2 The World Vegetable Center, Arusha, TANZANIA
}

\section{*Corresponding Author: tjmaginga@gmail.com}

Citation: Maginga, T. J., Nordey, T. and Ally, M. (2018). Extension System for Improving the Management of Vegetable Cropping Systems. Journal of Information Systems Engineering \& Management, 3(4), 29. https://doi.org/10.20897/jisem/3940

Published: November 10, 2018

\begin{abstract}
Horticulture as the part of agriculture sector plays the role for food security, economic growth and nutrition improvement. In developing countries where agriculture is regarded as the backbone of most countries' economy it draws attention for most governments as the main source of employment and livelihood for the majority. Agricultural extension has been the key facilitator for achieving high crop productivity and an enabler to knowledge resources for these countries. However, lack of clear information for vegetable cultivations, crop requirements, climatic information, pests and diseases to constantly help farmers to come up with proper potential yield of the vegetable crops reduce the potential of horticulture in improving the farmers livelihood and countries economic gain, Therefore, this study aims at bringing the ICT-enabled extension support system for farmers to help them make decision on proper ways of cultivating their crops based on locations' and timely climatic condition.
\end{abstract}

Keywords: extension system, web and mobile application, horticulture, vegetable cropping system

\section{INTRODUCTION}

For the past decades horticulture production including the vegetable farming has been the major drivers for change towards sustainable agriculture (Mabaya, 2015). In Tanzania, the strategy for horticulture development for 2012-2021 along with the establishment of Horticultural Development Council of Tanzania (HODECT, 2012) is demanding for the fast growing opportunities of the market in the country and abroad so as to improve nutritional status, increase incomes and reduce poverty while increasing productivity and quality of the products (Kang et al., 2009).

In other developed countries such as United States, Finland and China to mention a few also have a mechanism to help farmers for managing their crops through computer aided extension systems to maximize their output (Yan-E, 2011). According FAO reports, weak extension support systems explained in part the under productivity of cropping systems in developing countries (Kalim, 2005). In common given range, the production yield of vegetable crops like tomatoes can range between 40 - $100 \mathrm{t} / \mathrm{ha}$ depending on agroecological conditions and practices, but average tomato yields in sub Saharan countries (including Tanzania) are under 19.4 t/ha less than minimum production standard except for South Africa. In this given context there is a need for the country like Tanzania to adopt the use of ICT enabled extension system of which it will help farmers to enter into the foreign or international markets. 
Therefore this paper main focus is to bring the idea of using ICT- enabled extension support system for farmers, we hypothesize that the development of a new ICT will help farmers to better manage their vegetable cropping systems and maximize output and improve the yield potential of the vegetables to smallholder farmers and presented in this paper is the need for the developed extension support system for small holder farmers in order to help them make decision on ways of properly cultivating their crops in their areas based on locations' the climatic condition.

\section{Horticulture in Developing Countries}

In developing countries where agriculture is regarded as the backbone of these countries' economy, it draws attention of the governments as the main source of the population employment and livelihood (Ajapnwa et al., 2017). The horticulture sub-sector has grown efficiently and resulted into to food crops and source of exports (ISHS, 2015).

The development of the agricultural sector in Tanzania is being reinforced by several strengths including suitable soils, diverse climatic condition suitable for cultivation of a large range of horticultural crops. The crop production is mostly influenced by climatic changes and pests, crop pests and disease has become a serious threat to global food security and made life of farmers difficult (Kang et al., 2009). However the agricultural extension has been the key facilitator for achieving high crop productivity and an enabler to knowledge resources which can manage pests and crop diseases and most governments and agricultural stakeholders are trying to rejuvenate their extension systems (Raj, 2013).

The availability of clear information for vegetable cultivations, on crop requirements, the climatic information, pests and diseases and adaptation of these information to their location can help farmers to come up with proper potential yield of the vegetable crops, also it plays a very important role of improving the horticulture subsector of the agriculture (HODECT, 2012).

Currently the extension support system is being facilitated by the local methods being achieved by extension officer visits, conducting workshops and trainings given by the non-governmental organizations. Development of the ICT- enabled extension support system in relation to making information available will act as an agent to change agricultural situation and improve farmers' access to knowledge sharing and access to information. It is believed that ICT enabled extension nurture opportunities has the potential for helping farmers (Raj, 2013), and according to Tanzania Communication Regulatory Authority (TCRA) ICT sector overview, it shows that by the year 2017 internet users have progressively increased to 23 million people which is about $45 \%$ of the Tanzanian population being served by multiple internet service providers (ISPs) (Zacharia, 2018). The figure includes estimates of internet café users, organization/institution use, household and individual use (Hill, 2010).

From these given statistics, the development of the ICT- enabled extension support system in Tanzania can reach a large extent of the population and solve the information flow of the extension services provided to horticulture farmers.

\section{Extension Support Systems}

The extension support system concept talks of scientific techniques that includes new knowledge practices through education provision to farmers. In agriculture perspective it encompasses communication and training activities organized for people in the rural areas from different discipline of agriculture so as to facilitate interaction and foster collaborations within information system which includes agricultural research, agricultural education and information provision (Colen and Performance, 2013).

Agricultural extension services in Tanzania lies beneath the responsibility of the government, conducted locally by the Village Extension Workers. The whole structure is not adequate enough to reach about 2 villages of 1000 farmers for every extension officer and thus results to overwhelming division of works also these local extension systems are comprised with the other barriers such as transport and other limitations related to cultural taboos where women are denied access to extension services and from that fact the focus tend to deviate from all farmers to male farmers which means an extension officer cannot work as much perfect as they are supposed to work with every farmer (ISHS, 2015).

\section{Other Related Works}

The study conducted by Ngowi (Ngowi, 2015) had the objective to deliver a working prototype that will support agricultural stakeholder to have better flow of information. The study came up with an integrated web-based system to help small holder farmers getting information on the market channels for crops where by it allows farmers to upload the pictures for their crops to easily market their crop products and to bridge the gap between farmers and vendors.

According to Camilius, (Camilius, 2016) the need of ICT to support farmers has increased, in Tanzania some of the solutions that have been implemented by other researchers for the agricultural practices is the Agro-Advisory 
platform widely known as Ushauri Kilimo. The platform in an integrated system that has web based advisory information system that gives farmers access to advices in different agriculture issues like agronomic practices, livestock husbandry and other agricultural related information related to marketing information by sending any question through an SMS and get a response from an agricultural expert but currently the platform is not actively in use.

Tigo Tanzania has also introduced a solution for small holder farmers which is called mobile Tanzania farming app. To help farmers get up to date market information on how a farmer can get connected to the crop buyers which in turns will help farmers to make better decisions (Tanzania Invest, 2014).

Existing information systems for helping small holder farmers are farmer connect and Kilimo Salama. On the farmer connect application, agencies help farmers to tackle various challenges that are facing in their day to day agricultural practices but also the weather forecast information. The platform is also integrated with other portals to get accurate information on the policies for agricultural practices (Tanzania Invest, 2014). Kilimo Salama platform also has not diverged much from the farmer connect platform where by small holder farmers who are dealing with maize and wheat in this platform gets to receive insurance for their farm against drought and too much rain. With an information integrated from the weather stations the information acquired helps to calculate rainfall formula and in the end the payout to farmers is obtained. (Kilimo, 2010).

\section{PROPOSED SOLUTION}

The development of an extension support system is being presented as the solution for farmers access to information, where by this system is going to cover all the weather located regions in Tanzania and the expected platforms are going to be a web application and a mobile application in that context when a web application is being used it will help to acquire the feedback and help to incorporate in the mobile application. This methodology is supported by an iterative way of software development that will act as a roadmap for the development process because it allows the incorporation of the feedback.

\section{Extension Support System Modelling}

The extension support system as the source of all the cultivating information for vegetable growers has been modelled where all the information is coming from the right sources such as books and different articles being organized by the agronomist. An agronomist is going to provide the information through the platform from there data will be disseminated to farmers through extension officers and help the farmer to easily manage their cropping systems. Figure 1 shows the conceptual framework for the extension support system.

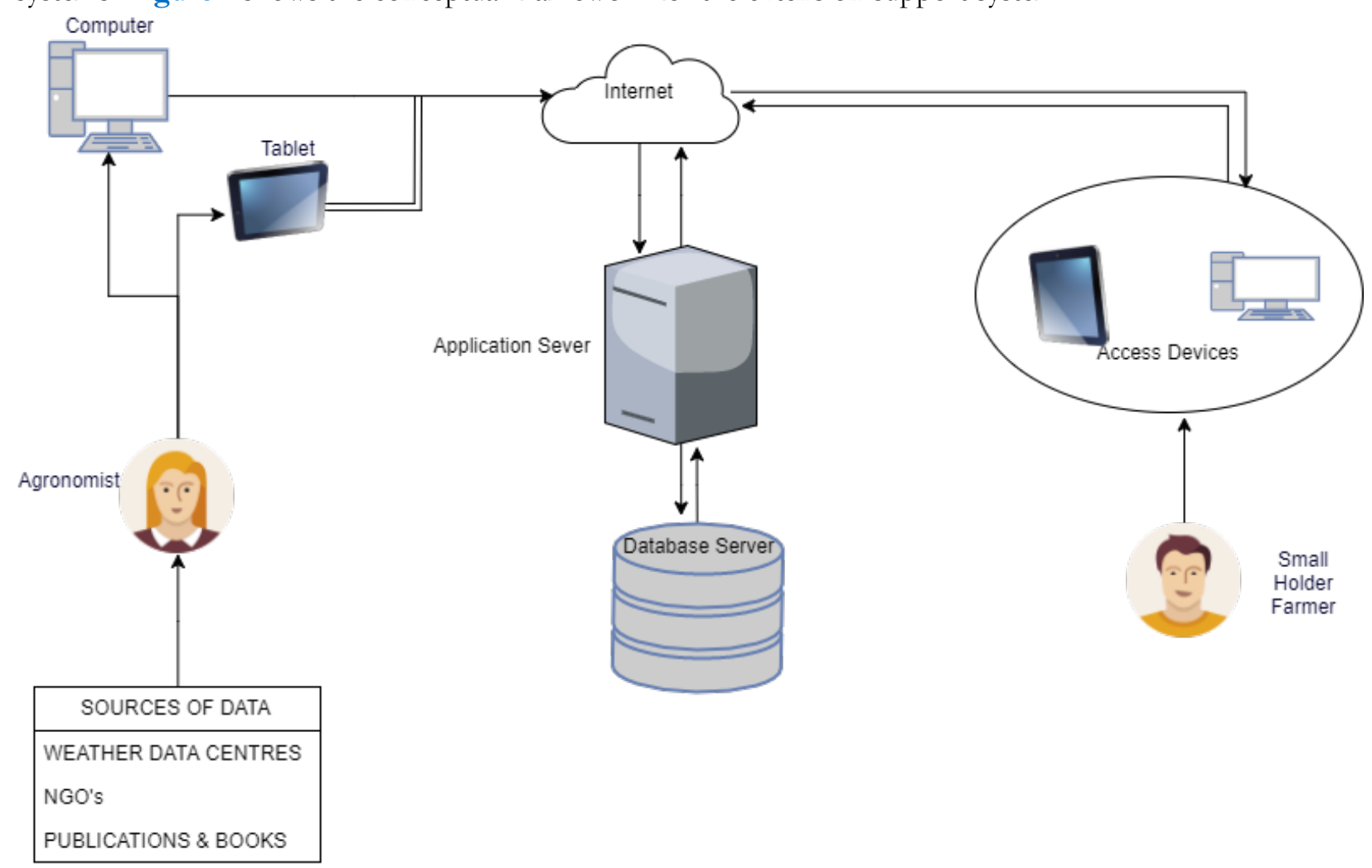

Figure 1. Conceptual framework for Extension support system 


\section{System Layout Images}

The implemented solution of the extension support system is currently on the web application comprised of the functionalities as shown on the pictures below. Figure 2 displays the home page of the software where users and authorized users (agronomists) have access to viewing and uploading the data for the system. On Figure 3 the system interface displays the weather stations for different location in Tanzania and the neighboring countries for the recorded temperature weather data in the database. Figure 4 the system picture to display number of crops available with their respective requirements, pests and diseases and best practices to be applied by the farmers when cultivating their vegetable crops. Figure 5 is the system picture showing the suggested best sowing period for a specific crop in a particular area, this graph shows the period for cultivation and the temperature data in that location through that period.

\begin{tabular}{rlllll}
\hline LAGROTOOL & & & & \\
HOME & LOGIN PAGE & USER ACCESS & FORUM & ABOUT & CONTACT
\end{tabular}

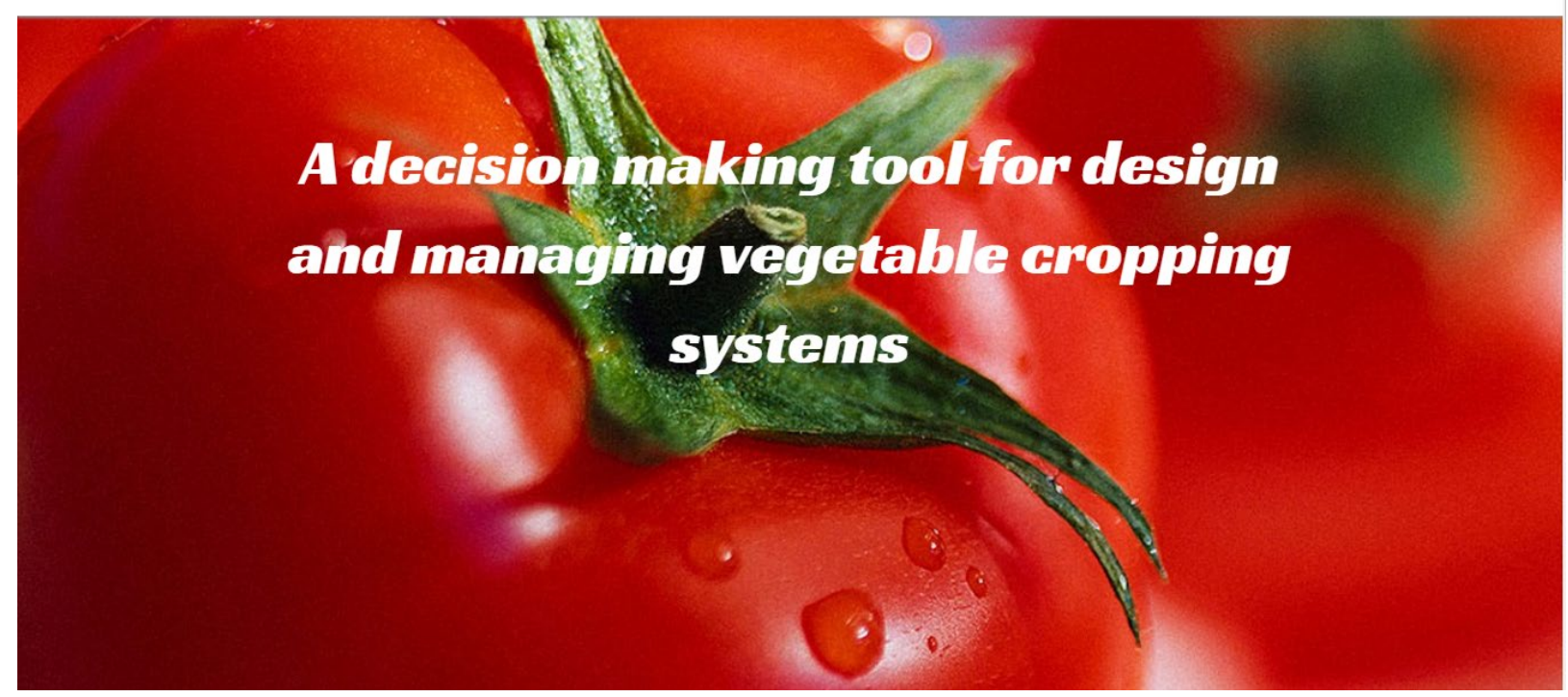

Figure 2. Home page for giving access to users for interacting with the system
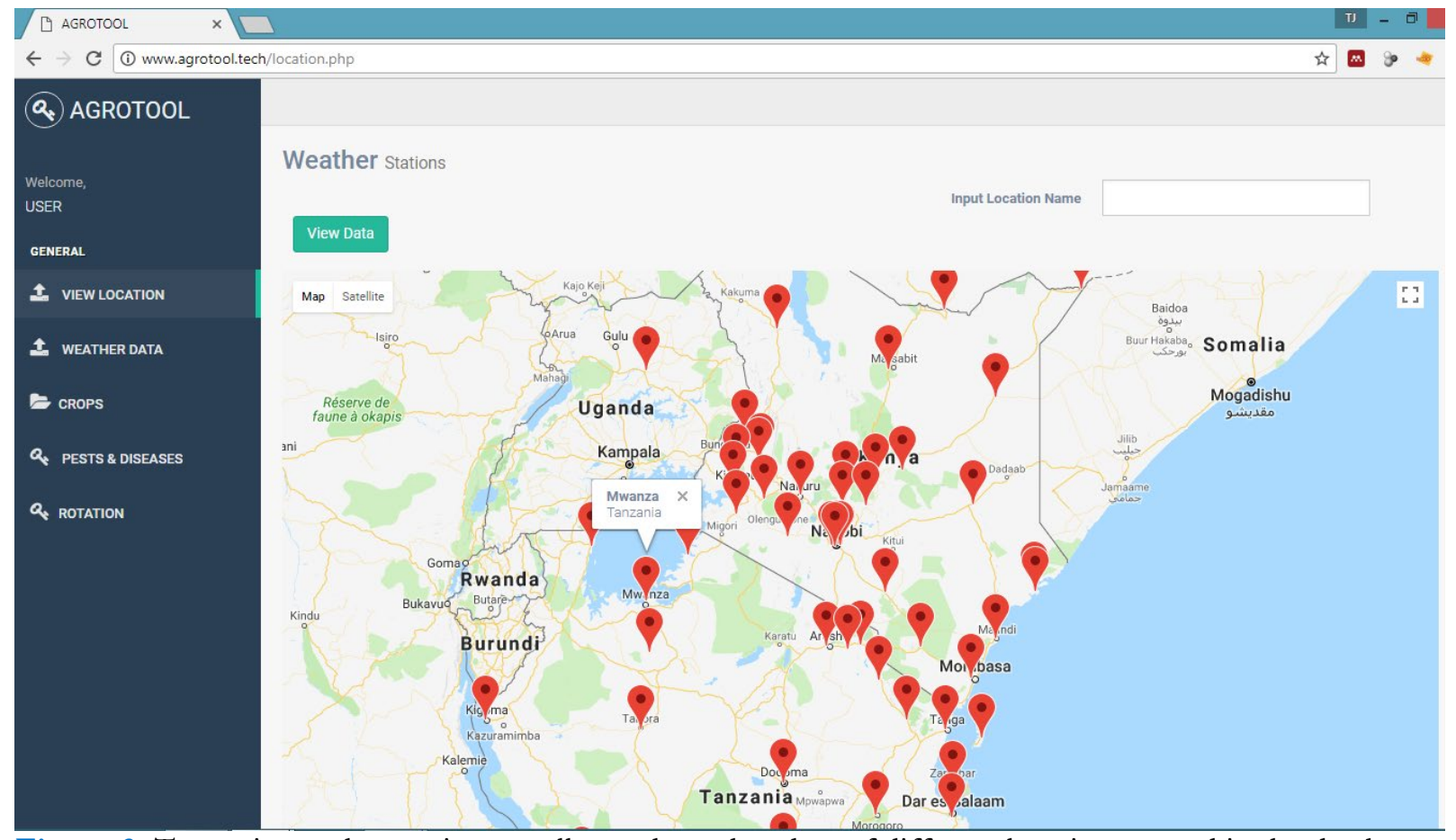

Figure 3. Tanzania weather stations to allocated weather data of different locations stored in the database 


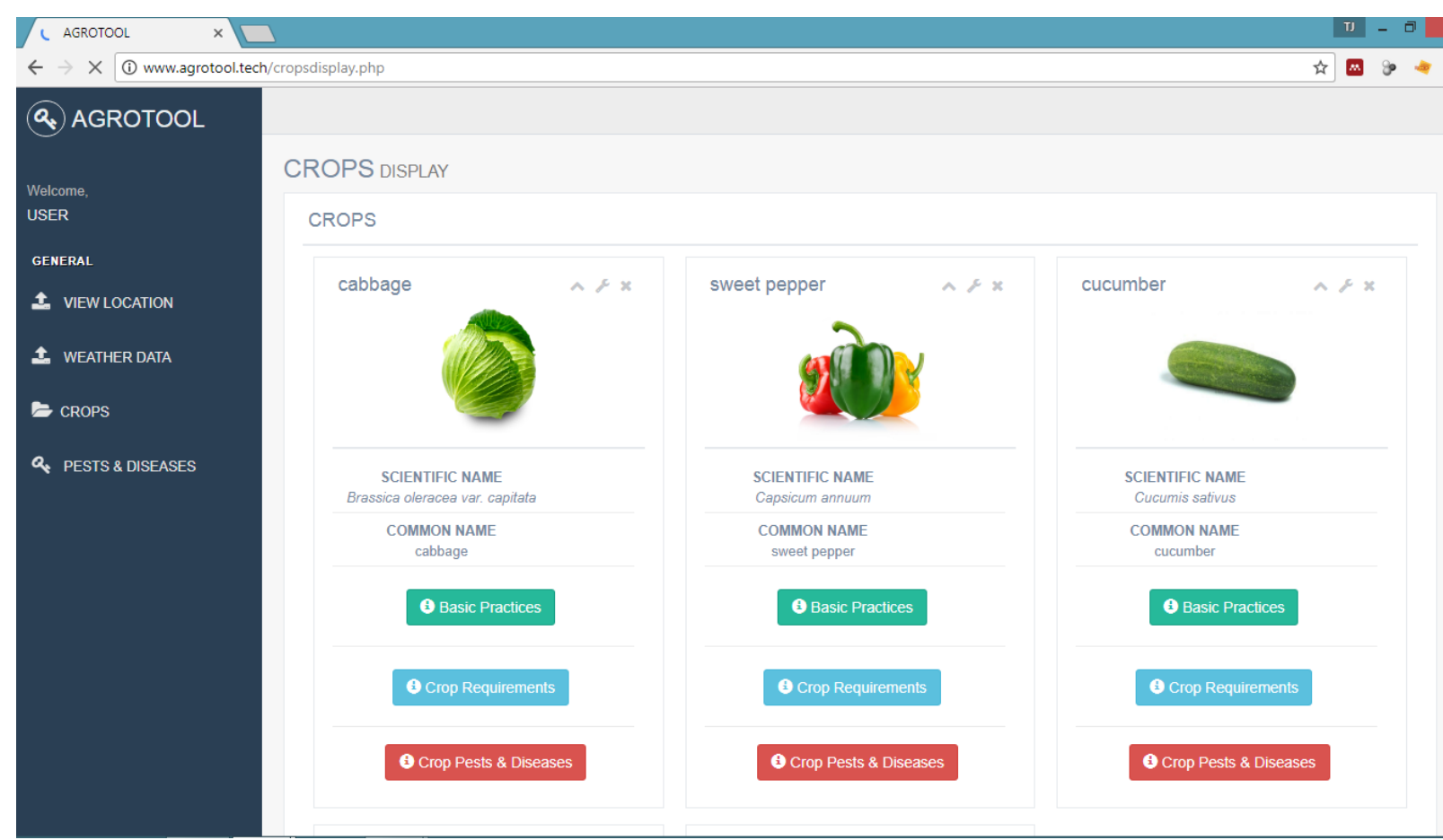

Figure 4. A page for displaying crops with their respective information on requirements, best practices, pests and diseases

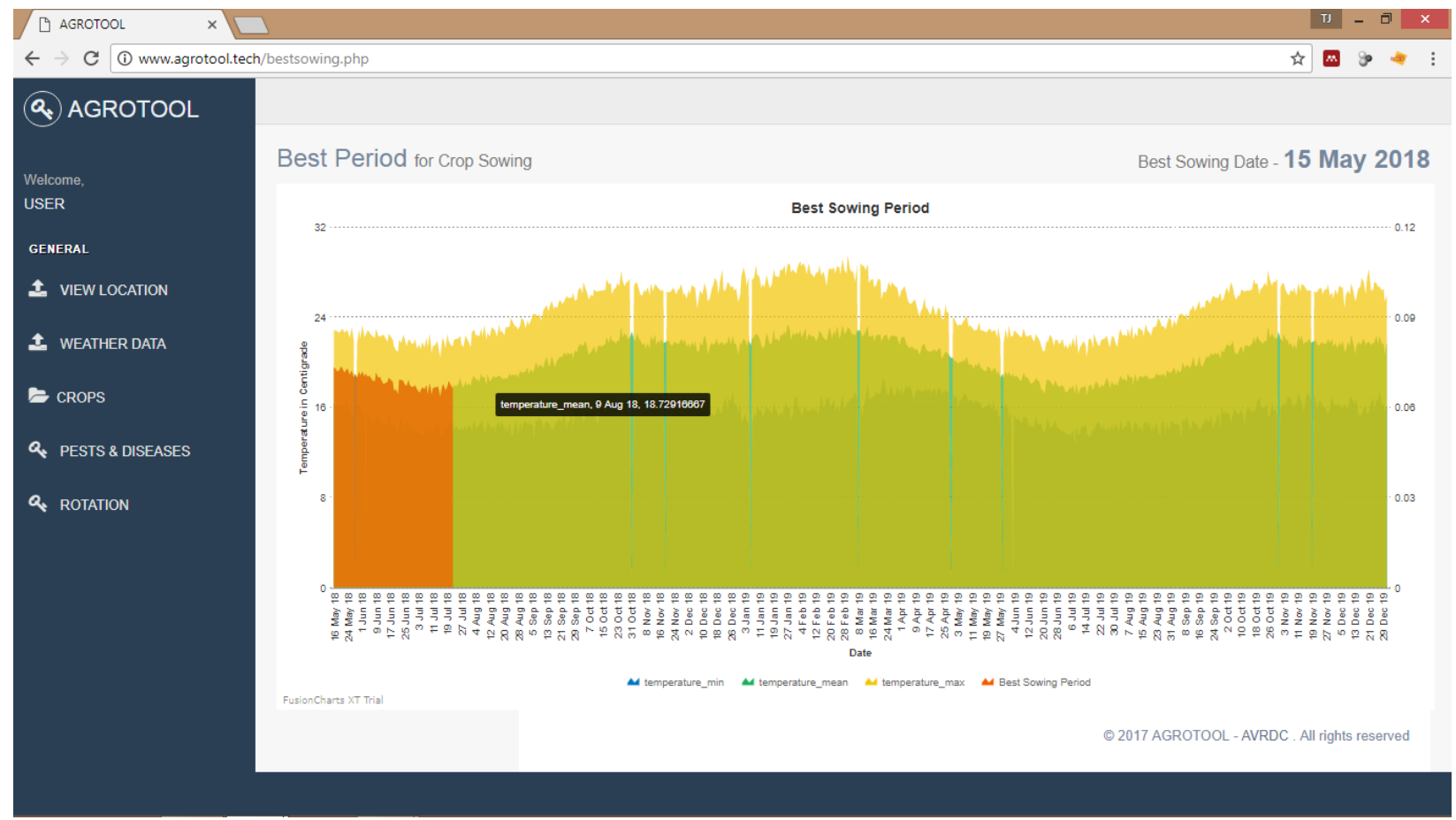

Figure 5. Graph for giving user a best sowing period suggestion based on the weather data in a particular selected location

\section{Features of the System}

The software will be able to operate on any computer machine with an access to the internet via web browser and also the mobile application to be developed will include all the features to operate on the mobile smart phones. The database will be installed on a remote machine and so it will require for users to have an access on the internet. The requirement specifications for the software development involve functional and non-functional requirements. Functional requirements capture the intended behavior of the system to perform the following functions. The functions depend on the user's level and permission package, Functional requirements will include user main functionalities as described on Table 1. 
Table 1. System main functionalities

\begin{tabular}{ll}
\hline Functionality & Description \\
$\begin{array}{l}\text { View Map for Weather } \\
\text { Stations (Locations) }\end{array}$ & $\begin{array}{l}\text { There is a list of locations, which has plan (map). This function allows the user with appropriate view the } \\
\text { locations in map by using google map feature by comparing the information of location data from the database. } \\
\text { When user moves the mouse, could see the location weather stations by markers. }\end{array}$ \\
$\begin{array}{ll}\text { View Weather Data } \\
\text { Designing a cropping }\end{array}$ & $\begin{array}{l}\text { The application will allow users to get average weather data for the whole year displayed in graphical format } \\
\text { of minimum, mean and maximum temperature per each month. }\end{array}$ \\
$\begin{array}{l}\text { The system will help user to choose a type of crop they want to plant and specify the sowing date, through } \\
\text { this functionality user will be able get the feedback on harvesting day and even the best sowing period. }\end{array}$ \\
Viewing information on
\end{tabular}

\section{User Classes and Characteristics}

There are three types of users on the system.

\section{Agronomist}

The first user will be an agronomist to be given an authorized privilege to gain access to the system, this user will be able to upload different types of information such as weather data, requirement of the crops and any other required information.

\section{Smallholder Farmer/Researcher}

The other user will be a small holder farmer or any user that will be interested on gaining access to the system. This user will be able to query the information on the weather data, types of crops and their requirements, rotation and cropping system also the pests and diseases information.

\section{Administrator}

The final user will be the system administrator who will be having the higher privileges than other users on the system, an administrator of the system can have all the privileges that all users have in the system and may also be able to grant some of the privileges to the users.

\section{Software Architecture}

The following are the key major functions of the software

- Providing user data on average weather data (temperature \& precipitation) on various weather stations in Tanzania

- A system will provide information on about seven vegetable crops and their requirements for proper cultivation procedures.

- The system will provide the information on possible effects and diseases that may affect those crops.

- The system will give user data on when is the proper period of time to start cultivating and the expected time to harvest but also the best sowing period for start sowing.

- The system added feature will be to provide a forum platform for farmers to ask questions and get response from the agronomists.

\section{METHODOLOGY}

\section{Study Area}

This study has been conducted in the country of Tanzania which endows almost 44 million hectares suitable for agriculture, only 14 million ha is cultivated according to Agricultural Sector Development Strategy due to the fact that some of the areas have low soil fertility, land degradation and drought. Until recently agriculture in Tanzania has been more based on land expansion for cultivation rather than focusing of high yield productivity.

\section{Data Collection}

The study conducted had different areas focused for data collection which includes regions such as Mwanza, Morogoro and Arusha based on the following criteria, these regions are located in the zones considered as the most horticultural production areas. Zones includes Northern Zone (Kilimanjaro, Tanga, Manyara and Arusha), Coastal Zone (Dar es salaam, Coast and Morogoro) and Lake zone (Mwanza) other zones includes central zone, Zanzibar and southern highland as shown on Figure 6. Data from farmers and extension officers has been collected for by using questionnaire since this method gave opportunity for farmers to provide feedback on their experience anonymously (Cohen et al., 2014) together with discussions with key informants and also data has been 
collected from agronomists through questionnaire and interviews and analyzed through tableau platform for data analysis.

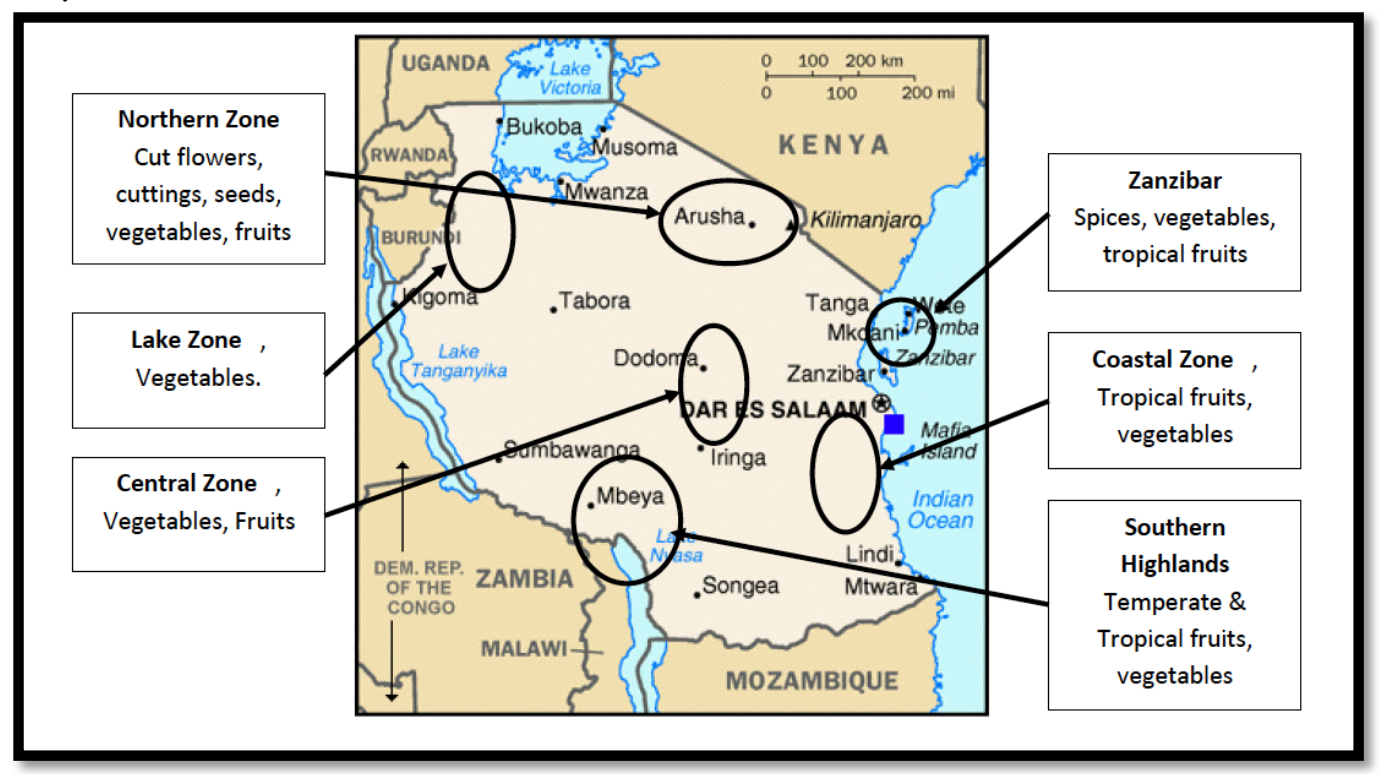

Figure 6. Tanzania map indicating main horticultural zone areas (Netherland, 2015)

\section{RESULTS \& DISCUSSIONS}

The study was focusing on an attempt to understand the use of information and communication technology devices for extension support systems to small holder farmers during managing their vegetable cropping systems. The researcher selected about 180 respondents residing in areas specified above 150 of them were small holder farmers which includes the small holder farmers and 30 were the agronomists, the survey was carried out to find the number of farmer who engage their vegetable cropping activities with the use information and communication technology for managing their vegetable cropping system through extension services. The results obtained from the survey were put through analysis platform called Tableau and presented as follows:

\section{Use of Technology Devices}

The use of technological devices for farmers included smart phones or any other related device for communication purposes, the following are the results of the responds to the question.

The results on Figure 7 imply that education level has impact on the use technological devices for meanwhile a large percent which is about $71.03 \%$ of users are using technological devices but $26.90 \%$ out of $28.90 \%$ are farmers with primary education level who are not using technological device but it doesn't setback any proposed technological solution for the farmers.

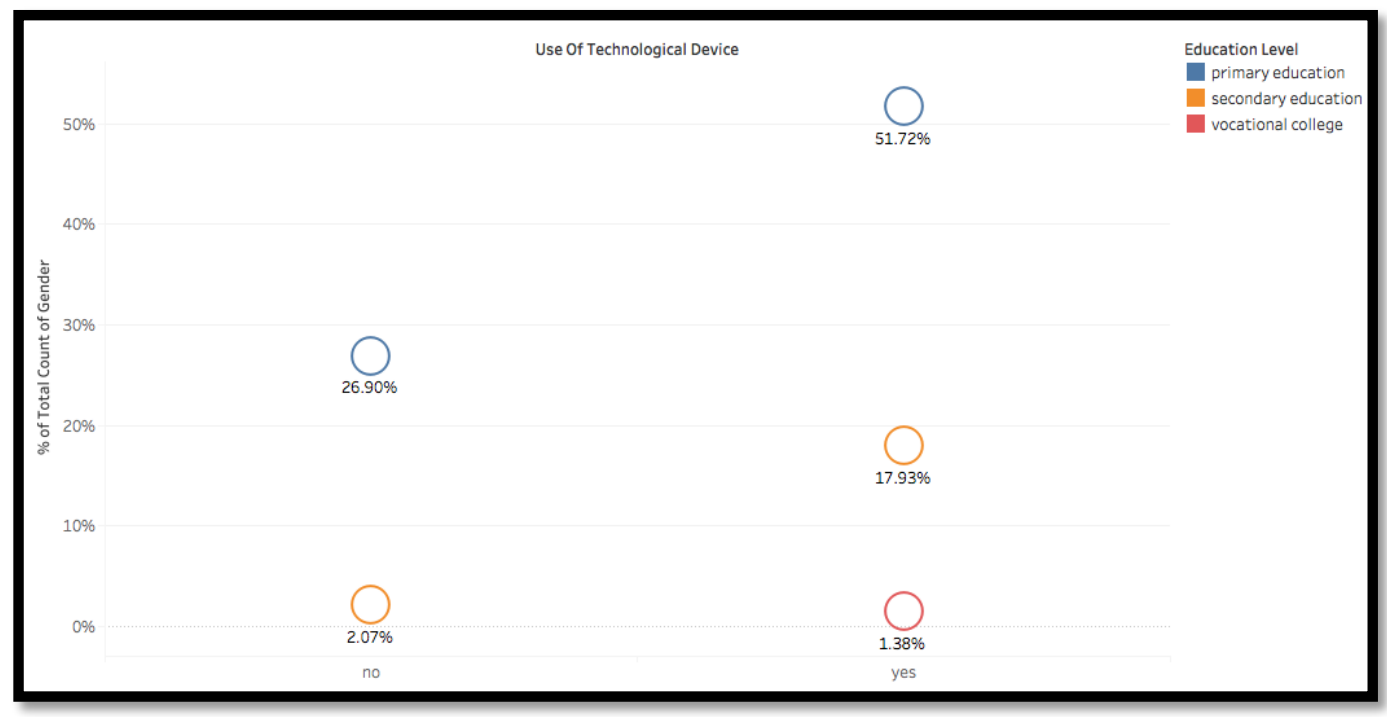

Source: survey for small holder farmers and extension officers (2018)

Figure 7. Use of technological devices for small holder farmers with education background

(C) 2018 by Author/s 


\section{Benefits Small Scale Farmers to use Technological Systems}

This part includes on how respondents think of the solution to be proposed for managing their vegetable cropping system. The results on figure vary from respondents to either agree or disagree to the idea of using technological solution for managing their vegetable cropping systems.

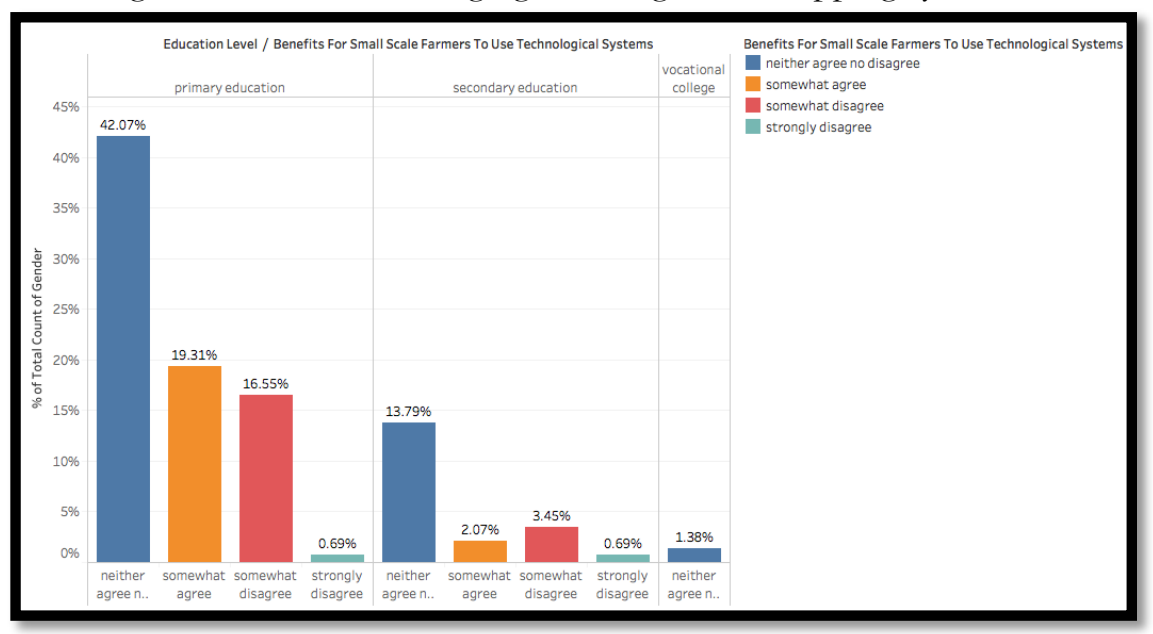

Source: survey for small holder farmers and extension officers (2018)

Figure 8. Benefits on the use of technological devices for small holder farmers with their educational level

The results on Figure 8 show that about $57.24 \%$ of the respondents neither agree or disagree with the benefits on the use of technological systems for small scale farmers to manage the vegetable cropping system. Meanwhile $1.38 \%$ disagree and $21.8 \%$ somewhat agree to the benefits brought by the use technological system for small scale farmers.

\section{Weaknesses on Available Extension Support System and Development of Technological Extension Support System}

The results shown on Figure 9 explain the data that was acquired from the agronomists through questionnaire to give a picture on the available extension support system for small holder farmers of which a total of $78.71 \%$ said yes, there are weaknesses and regardless of the response types all respondents agree that there is a need for developing a technological extension support system.

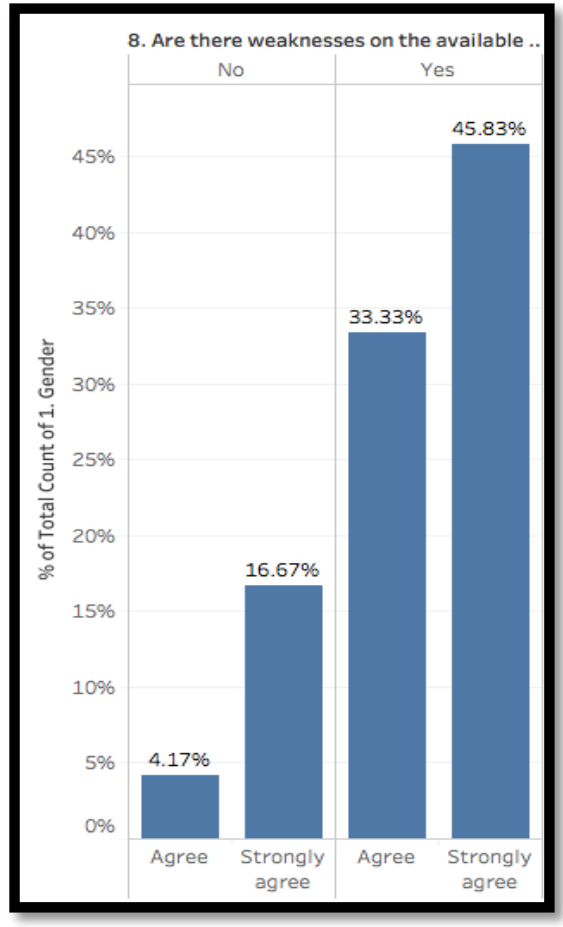

Source: survey for agronomists (2018)

Figure 9. Weaknesses on the available extension support system for small holder farmers 


\section{Usefulness of Technological Extension Support System}

Results on Figure 10 shows that the ideas of extension support system in not new to some of the agronomist but to some is a very new idea, in all of the given respondents there are not more than two extension support system seen by the agronomists and also these agronomists still support the fact that extension support system are useful for small holder farmers.

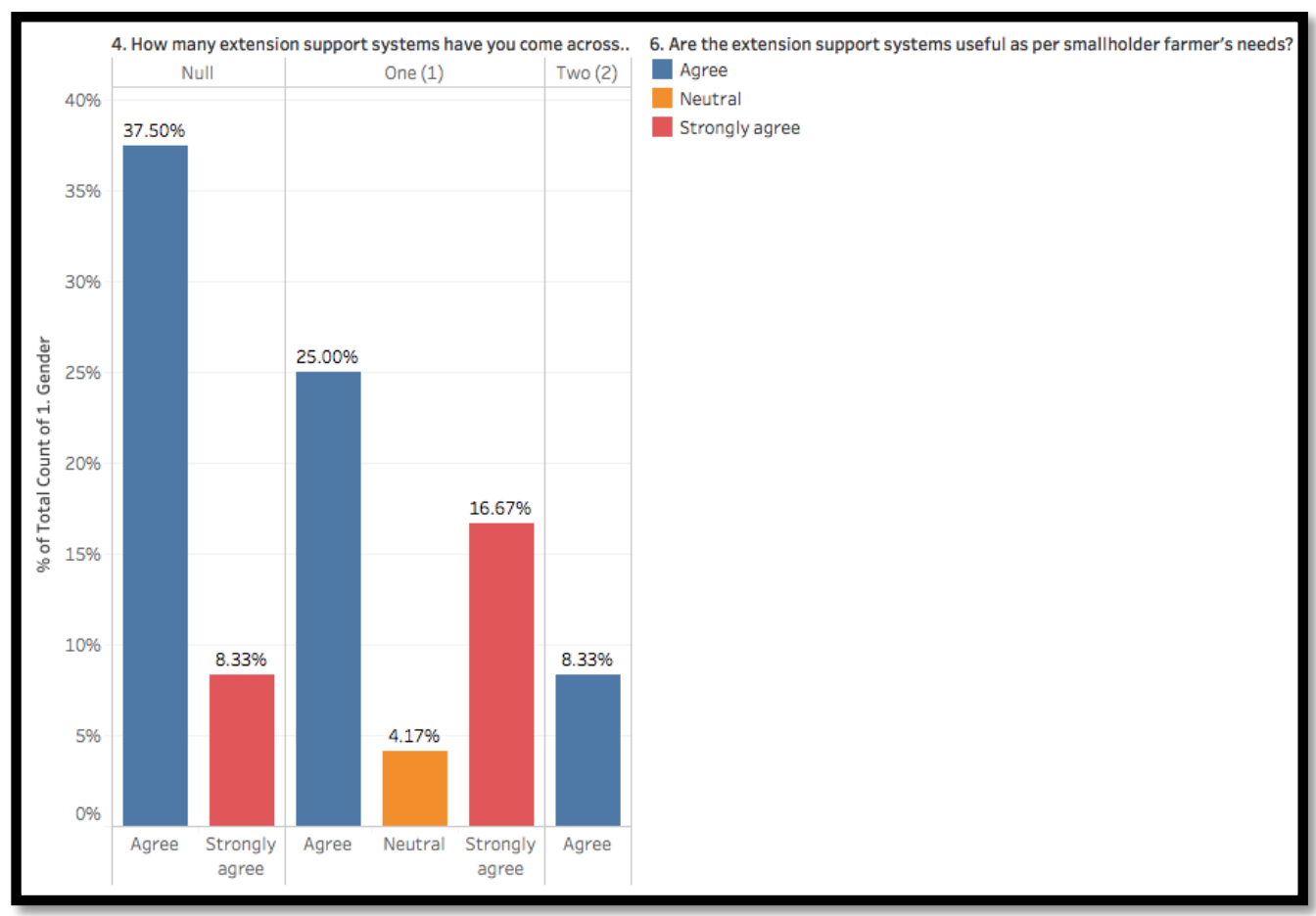

Source: survey for agronomists (2018)

Figure 10. Usefulness and number of extension support system as per agronomist's experience

\section{CONCLUSION}

The developed extension support system whose requirements specifications and functionalities have been narrated on this paper gives a clear flow of data and helps to provide farmers a better solution on how to use the given information for their day to day cultivation procedures. By taking advantage of internet penetration in the country and the use of technology, this application is directly going to benefit the small holder farmers with the support from of the extension officers on acquiring information about the best sowing periods and harvesting time with regards to its development farmers who are the majority will be supported by extension officers on the access to this information.

On the business perspective, development of this extension support system is going to help all the important stakeholders for the vegetable cultivation to have the appropriate system for managing their cropping system from best sowing period, calculating the harvesting period and being able to get the best practices information for their crops and to build knowledge ability for farmers to be able to fight against pests and diseases through natural ways. From these given facts the implementation of this ICT - enabled extension support system will enable smallholder farmers to come up with the highly produced vegetables of great potential and directly help them to win the market not just within the country but also on the international market. The designed system is user friendly and does not really need for users to have special skills on interacting with the system except for computer basic skills.

\section{ACKNOWLEDGEMENT}

This work is a part of the project supervised by The World Vegetable Centre AVRDC in Tanzania funded by CIRAD in France. However this work has also been facilitated by The Nelson Mandela African Institute of Science and Technology. 


\section{REFERENCES}

Ajapnwa, A. et al. (2017). Efficiency and productivity analysis of vegetable farming within root and tuber-based systems in the humid tropics of Cameroon. Journal of Integrative Agriculture. CAAS. Publishing services by Elsevier B.V, 16(8), pp. 1865-1873. https://doi.org/10.1016/S2095-3119(17)61662-9

Camilius. (2016). ICT based Agro-Advisory System from Tanzania|E-Agriculture. Available at: http://www.eagriculture.org/news/ict-based-agro-advisory-system-tanzania (Accessed 13 February 2018).

Cohen, L., Manion, L. and Morrison, K. (2014). Questionnaires - Data collection - General advice - LeTS Evaluation Resources - Resources - Strategy and Development - LeTS - The University of Sheffield. Available at: https://www.sheffield.ac.uk/lets/strategy/resources/evaluate/general/methods-collection/questionnaire (Accessed 29 June 2018).

Colen, L. and Performance, E. (2013). Constraints to smallholder participation in high-value agriculture in West Africa.

Hill, G. (2010). Understanding what is happening in ICT in Tanzania. Survival, 52(2), 105-116. https://doi.org/10.1080/00396331003764637

HODECT. (2012). Tanzania Horticultural.

ISHS, S. (2015). What is the Future of Horticultural Science in Africa? | International Society for Horticultural Science. Available at: https://www.ishs.org/news/what-future-horticultural-science-africa (Accessed 13 February 2018).

Kang, Y., Khan, S. and Ma, X. (2009). Climate change impacts on crop yield, crop water productivity and food security - A review. Progress in Natural Science. National Natural Science Foundation of China and Chinese Academy of Sciences, 19(12), 1665-1674. https://doi.org/10.1016/j.pnsc.2009.08.001

Kilimo. (2010). Fact sheet: Kilimo Salama "Safe Agriculture". pp. 1-9.

Kalim, M. Q. (2005). Modernizing National Agricultural Extension Systems: A Practical Guide for Policy-Makers of Developing Countries. Available at: http://www.fao.org/docrep/008/a0219e/a0219e03.htm (Accessed 11 March 2018).

Mabaya, E. (2015). The Impact of Agriculture Technology Adoption on Farmers' Welfare in Uganda and Tanzania. pp. 1-22.

Netherland, M. (2015). Tanzania Horticulture.

Ngowi, K. M. (2015). Semester Theme: Master's Thesis.

Raj, S. (2013). E-Agriculture Prototype for Knowledge Facilitation among Tribal Farmers of North-East India: Innovations, Impact and Lessons. Journal of Agricultural Education and Extension, 19(2), 113-131. https://doi.org/10.1080/1389224X.2012.718247

Tanzania Invest. (2014). Free Tanzania Farming App Connects Farmers - TanzaniaInvest. Available at: https://www.tanzaniainvest.com/agriculture/free-tanzania-farming-app-connects-farmers (Accessed 13 February 2018).

Yan-E, D. (2011). Design of intelligent agriculture management information system based on IoT. Proceedings - 4th International Conference on Intelligent Computation Technology and Automation (ICICTA), 1, 1045-1049. https://doi.org/10.1109/ICICTA.2011.262

Zacharia, A. (2018) Report: Number of internet users bits 23 m mark in TZ - Business $\mid$ The Citizen, The Citizen. Available at: http:/ / www.thecitizen.co.tz/News/Business/Report--Number-of-internet-users-hits-23m-mark-in-

TZ/1840414-4312348-r6cru3z/index.html (Accessed 1 March 2018). 